\title{
SQUAMOUS CELL CARCINOMA IN THE PARANASAL SINUSES IN HORSES: CASE REPORT
}

\author{
SENE, N. ${ }^{1}$; MICHELOTTO P.V. ${ }^{2}$, LANGARO, R.A. ${ }^{1}$, RAMOS, C.G. $^{2}$ \\ ${ }^{1}$ Médica Veterinária - PUC-PR; \\ ${ }^{2}$ Pontifícia Universidade Católica do Paraná.
}

Paranasal sinuses tumors in horses are uncommon, being the squamous cell carcinoma the most prevalent of them. The clinical signs are usually inespecific for this kind of tumour, and are related with the development phase. Paranasal sinuses tumours in horses refers unilateral nasal discharge, usually in the affected side. The secretions are normally fetid and varies between mucopurulent to serosanguinous. Epistaxis can occur in severe cases. Facial swelling and deformation of the facial bones occur in advanced stages. A 15 year-old gray Percheron mare was examined at the Large Animal Hospital of the Pontifícia Universidade Católica (Paraná State), refering a significant swelling $\left(25 \mathrm{~cm}^{3}\right)$ of the face, at the right maxilar sinuses, with a two month evolution. The radiographic study of the maxilar sinuses and dental arch, evidenced a superior third molar fracture. During the oral cavity examination, with the patient sedated, the superior fourth pre molar, first, second and third molars were extracted, being completely devitalized. It was performed the trephination of the caudal and rostral right maxilary sinus cameras, being curetted and daily flushed with saline with povidone in a $10 \%$ solution. The initial therapeutic program included penicilin (6 million IU) IM/b.i.d., gentamicin $(6.6 \mathrm{mg} / \mathrm{kg}$ ) IV/s.i.d. in saline and flunixin meglumine $(1 \mathrm{mg} / \mathrm{kg}) \mathrm{IV} / \mathrm{s}$.i.d.. The clinical situation did not improve and the treatment was changed. The sinus was cleaned with potassium permanganate b.i.d.; phenylbutazone (4 $\mathrm{mg} / \mathrm{kg}$ IV, s.i.d. and triclorometiazide with dexametasone (naquasone). Hematological findings evidenced anemia, leukocytosis and lymphopenia. Later, the lavage solution was changed for saline with rifanpin. The patient developed apathy, inapetence, weight loss, right side epistaxis, fever, enlargement of the right submandibular lymphnode, tachycardia and tachypnea. The nasal discharge became more fetid. A bacteriological analysis evidence Pseudomonas sp. and Streptococcus sp., and the ceftiofur $(3,0 \mathrm{mg} / \mathrm{kg}) \mathrm{IV} / \mathrm{s}$.i.d. was selected. Because of the worsening of the clinical signs and right eye blepharophymosis, humane euthanasia was proceded. The necropsy revealed pronunced tissue invasion occupying the maxilar and frontal sinuses, periocular region and maxilar, mandibular and turbinate bones. Histopathogic evaluation confirmed fibrose osteodistrophy and a highly invasive squamous cell carcinoma. This case showed the importance of including the squamous cell carcinoma in the differential diagnosis of facial bones enlargement, with the paranasal sinuses, involvement in equine patient. Also, the inclusion of a biopsy procedure would favour an early definitive diagnosis.

Key Words: paranasal sinuses, equine, carcinoma. 